\title{
SUZANNE DAVEAU \\ CINQUENTA ANOS DE ACTIVIDADE CIENTÍFICA E ACADÉMICA
}

\author{
ANTÓNIO DE BRUM FERREIRA ${ }^{1}$
}

\begin{abstract}
A Professora Suzanne Daveau é detentora de um curriculum científico e académico notável. Não sendo possível resumir em escassas páginas uma actividade tão rica e variada, limitar-me-ei a sublinhar aqui alguns passos do seu invulgar percurso de investigadora e de docente universitária ${ }^{2}$.

Suzanne Blanche Daveau nasceu em Paris, em 13 de Julho de 1925. Em 1947, licenciou-se em Geografia na Universidade de Paris, e obteve o título nacional de «Agrégée de Géographie», dois anos mais tarde.

Sucessivamente, Professora no Liceu de Gap (1949-50), Assistente na Faculdade de Letras de Besançon (1950-52), e Professora no Liceu de Lille (1952-53), em 1953 consegue o lugar de «Attachée de Recherches» no «Centre National de la Recherche Scientifique (CNRS)», lugar que mantém até 1957, ano em que obtém o Doutoramento em Letras na Universidade de Paris (Sorbonne). Apresentou então uma tese inovadora sobre a região de fronteira franco-suiça do Jura, intitulada «Les Régions Frontalières de la Montagne Jurassienne. Étude de Géographie Humaine» e publicada dois anos mais tarde (Mémoires et Documents, Institut des Études Rhodaniennes de l'Université de Lyon, $\mathrm{n}^{\circ} 14,571$ p.).

Antes, porém, Suzanne Daveau havia publicado vários artigos sobre temas diversos, desde a Geografia Rural à Geografia Histórica, tais como: «Un pays de côte: la bordure sud-est du Pays d'Othe», Mémoires et Documents, CNRS, 2, Paris, 1950, p. 175-188; «L'estivage des vaches suisses dans le Jura Français», L'Information Géographique, 17, Paris, 1953, p. 56-65; «Une communauté jurassienne au XVIII ${ }^{\mathrm{e}}$ siècle: les Foncine», Revue de Géographie de Lyon, 29, Lyon, 1954, p. 117-129.
\end{abstract}

1 Professor Catedrático da Faculdade de Letras da Universidade de Lisboa. Centro de Estudos Geográficos, Fac. Letras, Cidade Universitária, 1699 Lisboa Codex. Tel: (351-1) 79402 18; fax: (351-1) 7938690

2 Este texto corresponde, no essencial, com algumas adaptações de estilo e alguns complementos bibliográficos, ao discurso proferido pelo signatário na cerimónia de concessão do grau de Doutor Honoris Causa à Professora Suzanne Daveau, que se realizou na Aula Magna da Reitoria da Universidade de Lisboa, em 28 de Maio de 1997. 
A seguir ao seu doutoramento em Paris, e com a juventude dos seus trinta e dois anos, Suzanne Daveau abandona as comodidades da sua terra natal e parte para África, onde vai iniciar um dos períodos mais fecundos da sua carreira de investigação.

Em Outubro de 1957 é nomeada «Maître de Conférences» na Faculdade de Letras e Ciências Humanas da Universidade de Dakar e, em Maio de 1960, obtém aí a Cátedra de Geografia Física, lugar que ocupou até Setembro de 1964. Neste mesmo ano é nomeada responsável por um grupo interdisciplinar do CNRS, que terá como missão o estudo do Quaternário da Mauritânia. E assim vai cimentar-se uma das mais fortes componentes da formação científica da Professora Suzanne Daveau, a do estudo do mais recente período da História da Terra, marcado por acontecimentos tão relevantes como as glaciações e o próprio aparecimento do Homem.

A produção científica deste ciclo africano é enorme. Apesar do carácter sucinto desta apresentação, não posso deixar de citar alguns títulos mais salientes: «Recherches Morphologiques sur la Région de Bandiagara», Mémoires de l'Institut Français d'Afrique Noire, 56, Dakar, 1959, 120 p.; «Les Plateaux du Sud-Ouest de la Haute Volta. Étude géomorphologique», Travaux du Département de Géographie, Faculté des Lettres et Sciences Humaines de Dakar, 7, Dakar, 1960, 61 p.; «Cuirasses et chaînes birrimiennes en Haute-Volta» (de colaboração com M. Lamothe e G. Rougerie), Annales de Géographie, 387, Paris, 1962, p. 460-482; «Principaux types de paysages morphologiques des plaines et plateaux soudanais dans l'Afrique de l'Ouest», L'Information Géographique, 26, Paris, 1962, p. 61-72; «Anciens terroirs gangara» (de colaboração com Ch. Toupet), Bulletin de l'Institut Français d'Afrique Noire, B, 25, Dakar, 1963, p. 193-214; «Étude de versants gréseux dans le Sahel mauritanien», Mémoires et Documents, CNRS, 9, Paris, 1963, p. 3-30; «Façonnement des versants de l'Adrar mauritanien», Zeitschrift für Geomorphologie, Suppl.-Bd. 5, Berlin-Nikolassee, 1964, p. 118-130; «Dunes ravinées et dépôts du Quaternaire récent dans le Sahel mauritanien», Revue de Géographie de l'Afrique Occidentale, 1-2, Dakar, 1965, p. 7-42.

Quando, em 1965, se instala em Portugal, pela mão do Professor Orlando Ribeiro, Suzanne Daveau é, assim, uma investigadora em plena maturidade e com um já notável curriculum científico.

Entretanto, entre outros cargos e funções, Suzanne Daveau fora colocada no CNRS, de Outubro de 1962 a Setembro 1963, como Directora de Investigação e, de Outubro de 1964 a Setembro de 1965, foi Professora na Faculdade de Letras e Ciências Humanas de Besançon.

Depois de um curto período de «congé pour convenances personnelles», como refere no seu próprio currículo, Suzanne Daveau é colocada no Centro de Estudos Geográficos, em Março de 1966, como Directora de Investigação da Fundação Calouste Gulbenkian, e, em Novembro de 1970, inicia as suas funções de Professora na Faculdade de Letras de Lisboa. Começa, assim, um novo ciclo da vida da Professora Suzanne Daveau, que vai marcar profundamente o ensino e a investigação da Geografia em Portugal.

Logo em 1966, funda, juntamente com Orlando Ribeiro e Ilídio do Amaral, a Finisterra, Revista Portuguesa de Geografia, na direcção da qual se mantém durante trinta anos e de que vai ser grande impulsionadora e activa colaboradora 
científica. O primeiro artigo que publica na sua Revista, «Les rebords de plateaux gréseux d'Afrique occidentale et leur occupation humaine» (Finisterra, Revista Portuguesa de Geografia, 2, 1966, p. 149-187), é ainda o resultado da sua experiência africana, mas não vai tardar a publicação de artigos e de outras obras fundamentais sobre diversos aspectos da Geografia de Portugal.

Desde o princípio também, e antes de ensinar oficialmente na Faculdade de Letras de Lisboa, a Professora Suzanne Daveau preocupou-se com a preparação científica dos jovens que iniciavam os primeiros passos na sua carreira de investigação no Centro de Estudos Geográficos. Uma das suas primeiras actividades foi a orientação de um seminário sobre a utilização da fotografia aérea, que ela considerava, e considera ainda, com toda a justeza, um dos principais pilares da pesquisa geográfica. Não é assim por acaso que a sua primeira contribuição para a geografia portuguesa, publicada no primeiro volume da revista Finisterra («Rebordo sul da serra de Montejunto na região de Cabanas de Torres», Finisterra, Revista Portuguesa de Geografia, 2, 1966, p. 288-290), tenha sido a análise de uma fotografia aérea, mostrando todos os recursos que um geógrafo pode retirar deste documento, em vários aspectos da Geografia Física e da Geografia Humana.

Outra das suas preocupações foi a iniciação ao trabalho de campo, trazendo, do meu ponto de vista, como principal novidade, em relação ao trabalho que por cá se fazia no domínio da Geomorfologia, uma mudança na escala de análise, dando particular atenção ao funcionamento das vertentes e ao modelado de pormenor. Uma excelente iniciação ao trabalho de campo foi-nos dada por Suzanne Daveau, logo nos primeiros anos da sua estada em Portugal, em torno da evolução da vertente ocidental da Serra de Candeeiros, num estágio que se concretizava aos fins de semana. A variedade dos problemas, a vivacidade das discussões (uma vez por outra também participaram o Professor Orlando Ribeiro, o Professor Ilídio do Amaral e o Professor Galopim de Carvalho), as hesitações nos caminhos a seguir, tudo isso foi uma experiência fundamental para jovens habituados até então à ciência feita das aulas e das excursões.

Suzanne Daveau foi herdeira dos grandes temas em debate na Geomorfologia de Portugal. O mais clássico de todos era o da evolução da Cordilheira Central e bacias tectónicas envolventes, que já havia ocupado, durante largos anos, Orlando Ribeiro e Pierre Birot, esse grande cientista francês, a quem a geografia portuguesa tanto deve. Com a ajuda financeira do então Instituto de Alta Cultura, nasceu sob a orientação de Suzanne Daveau um projecto de investigação que, desde o início dos anos 70 até meados da década de 80 , foi um símbolo da pesquisa geomorfológica em Portugal. Os resultados dessa pesquisa, apresentados primeiro em relatórios de difusão restrita ou em artigos de revista, foi depois reunida numa imponente monografia em dois volumes, escrita por Suzanne Daveau, com a colaboração de Pierre Birot e de Orlando Ribeiro, e que constitui uma obra de referência da geomorfologia peninsular (Les Bassins de Lousã et d'Arganil. Recherches géomorphologiques et sédimentologiques sur le massif ancien et sa couverture à l'Est de Coimbra, Memórias do Centro de Estudos Geográficos, 8, Lisboa, 1985$-86,450$ p.). 
Não constituindo trabalhos de fôlego comparável ao dedicado às bacias da Lousã e de Arganil, mas certamente mais originais no âmbito das preocupações da geomorfologia portuguesa, figuram as diversas publicações de Suzanne Daveau sobre o Quaternário de Portugal, nomeadamente as relativas às manifestações de climas frios do Quaternário recente.

No que se refere às manifestações glaciárias, as preocupações já eram antigas, mas o único estudo sólido existente era o trabalho clássico de Lautensach, publicado na Alemanha em 1929, sobre a glaciação da Serra da Estrela. Esse estudo foi retomado por Suzanne Daveau que, num artigo publicado em 1971 ( «La glaciation de la Serra da Estrela», Finisterra, Revista Portuguesa de Geografia, 11, p. 5-40), aduziu precisões importantes no que se refere à dinâmica e à extensão dos glaciares naquela montanha. Por outro lado, a mesma autora deu uma contribuição decisiva para a confirmação da existência de manifestações glaciárias de baixa altitude nas montanhas do Minho, quer apoiando o estudo de Coudé-Gaussen sobre as serras da Peneda e do Gerês, quer através de investigações pessoais, que publicou em colaboração.

Foi, no entanto, no domínio das manifestações periglaciárias que os seus estudos deram os resultados mais inovadores no âmbito da Geomorfologia de Portugal, e que iriam exercer grande atracção sobre a generalidade dos geomorfólogos portugueses. Primeiro, foi um artigo publicado na Finisterra, em 1973, sobre a evolução quaternária das vertentes em Portugal («Quelques exemples d'évolution quaternaire des versants au Portugal», Finisterra, Revista Portuguesa de Geografia, 15, p. 5-47), que marca uma viragem nas preocupações temáticas da geomorfologia portuguesa. Depois, uma comunicação apresentada em França, em 1978 («Le périglaciaire d'altitude au Portugal», Colloque sur le périglaciaire d'altitude du domaine méditerranéen et abords, Strasbourg, p. 63-78), em que são analisadas, de maneira mais sistematizada, as manifestações geomorfológicas do arrefecimento quaternário nas montanhas do Centro e Norte de Portugal.

Se a contribuição de Suzanne Daveau para os progressos da Geomorfologia de Portugal foi da maior importância, a sua influência sobre o desenvolvimento dos estudos de Climatologia foi, talvez, ainda mais decisiva. Na verdade, enquanto a investigação geomorfológica estava bem enraizada na escola geográfica portuguesa, que contava na sua produção com trabalhos de valor internacional e incluía nomes de grande prestígio (lembro os de Orlando Ribeiro, Mariano Feio e Fernandes Martins), o mesmo não se pode dizer quanto à investigação de índole climatológica. E, no entanto, Portugal dispunha de uma valiosa documentação, regularmente publicada pelo então Serviço Meteorológico Nacional, que se mantinha praticamente desaproveitada pelos geógrafos.

Cabe a Suzanne Daveau o mérito de ter iniciado a análise sistemática desses dados, a sua representação cartográfica e a sua interpretação, tarefa em que envolveu, na maior parte dos casos, jovens colaboradores, alguns dos quais enveredaram mais tarde pela investigação em Climatologia. Esse trabalho revelou-se bastante fecundo. Já em 1972, Suzanne Daveau publicou um interessante artigo sobre a distribuição das chuvas muito fortes, à escala do ano, do mês e do dia («Répartition géographique des pluies exceptionnellement fortes au Portugal», Finisterra, 
Revista Portuguesa de Geografia, 13, p. 5-28), que pôs em evidência a grande irregularidade de ocorrência da precipitação no nosso país, facto que, obviamente, não poderia ser avaliado pelos valores médios, privilegiados então pelas estatísticas oficiais. Um outro artigo, publicado em 1975, refere-se à influência da continentalidade no ritmo térmico em Portugal («Influence de la continentalité sur le rythme thermique au Portugal», Finisterra, Revista Portuguesa de Geografia, 19, p. 5-52), com base num transepto Oeste-Leste, ilustrado essencialmente pelas estações climatológicas de Cabo da Roca, Lisboa e Elvas. A utilização de dados simples põe em evidência contrastes térmicos surpreendentes (por exemplo, amplitude anual de $6,8^{\circ} \mathrm{C}$ em Cabo da Roca e de $16,8^{\circ} \mathrm{C}$ em Elvas), enquanto o estudo sinóptico de situações reais mostra quão flutuante é o tempo atmosférico em Portugal, em que o jogo das massas de ar baralha fortemente o ritmo astronómico da variação das temperaturas.

Mas a obra-mestra, no domínio da Climatologia, é um volume sobre a Repartição e Ritmo das Precipitações em Portugal, publicado por Suzanne Daveau em 1977, com a colaboração de três jovens investigadoras (Répartition et Rythme des Précipitations au Portugal, Memórias do Centro de Estudos Geográficos, 3, Lisboa, 192 p.), que inclui, como peças fundamentais, dois mapas de Portugal na escala de 1:500.000: um sobre os valores da precipitação e o outro sobre o número de dias de precipitação, ambos referentes às médias anuais de 1931-60. O primeiro desses mapas, sobretudo, constitui uma belíssima representação de um dos principais factores da diversidade geográfica de Portugal. O livro, em si, trata dos problemas metodológicos encontrados e da explicação do ritmo e, fundamentalmente, da repartição espacial das chuvas. Um aspecto essencial consiste na influência que o relevo exerce sobre a circulação das massas de ar: subidas, descidas, convergências e divergências, que se traduzem marcadamente na diversidade regional e local da precipitação. Esse assunto foi retomado por Suzanne Daveau, em1978, numa revista de projecção internacional («La répartition des précipitations en fonction du relief: étude du cas portugais», Geoforum, 9, Oxford, p. 425-433). Mais tarde viria a realizar mais dois mapas, um relativo ao nevoeiro e à nebulosidade e outro dedicado aos contrastes térmicos, também em colaboração com jovens investigadores (Mapas Climáticos de Portugal. Nevoeiro e Nebulosidade. Contrastes Térmicos, Memórias do Centro de Estudos Geográficos, 7, Lisboa, 1985, 96 p), e que constituem, no dizer da própria autora, «imagens completamente novas de importantes aspectos do clima de Portugal».

Detive-me um pouco nos trabalhos de Geomorfologia e de Climatologia, por pensar que foi nestes domínios que a Professora Suzanne Daveau mais marcou a Geografia Portuguesa. Mas a sua obra tocou muitos outros aspectos, talvez mais inovadores nos temas e na metodologia, que muito contribuiram para a renovação do ensino e da investigação não só na Geografia mas também em ciências vizinhas, como sejam a Geografia Histórica, as relações entre a Geografia e a Arqueologia e, no domínio das técnicas, a Cartografia e a Teledetecção remota.

Nos vinte e cinco anos em que foi Professora da Faculdade de Letras de Lisboa, muitos foram os alunos que puderam beneficiar do seu ensino claro e rigoroso, e alguns tiveram mesmo o privilégio de conviver com ela e beneficiar dos seus ensi- 
namentos desde os primeiros anos da Faculdade até se tornarem seus colegas. A Professora Suzanne Daveau dirigiu com sucesso mais de uma dezena de teses de doutoramento, e discípulos seus são hoje professores na Faculdade de Letras de Lisboa, na Faculdade de Ciências Sociais e Humanas da Universidade Nova de Lisboa, na Faculdade de Letras do Porto e na Universidade de Évora.

A Professora Suzanne Daveau preocupou-se sempre em elaborar textos para o ensino e textos de divulgação da ciência que pratica. Alguns dos seus artigos de síntese tiveram eco para além das fronteiras da Geografia. Entre estes últimos, gostaria de citar um artigo publicado, em 1980, na Clio-Revista do Centro de História da Universidade de Lisboa, com o título, «Espaço e tempo. Evolução do ambiente geográfico de Portugal ao longo dos tempos pré-históricos» (Clio, II, p. 13-37). Cuido saber que este ensaio teve um muito favorável acolhimento no meio dos arqueólogos portugueses, que encontraram nele um caminho provável para o enquadramento geográfico das suas descobertas. Mas não podemos esquecer o seu livro de síntese da Geografia Física, o Ambiente Geográfico Natural, publicado pela primeira vez em 1976 (Imprensa Nacional - Casa da Moeda, Lisboa, 135 p.) e que vai na $3^{a}$ edição (Ed. João Sá da Costa, Lisboa, 1996). Antes, em 1973, havia publicado, com a colaboração de Orlando Ribeiro, um desenvolvido manual universitário, na conhecida «Collection U», da Armand Colin, com o título, La Zone Intertropicale Humide (Paris, 276 p.). Muito recentemente publicou outro livro, o Portugal Geográfico (Ed. João Sá da Costa, Lisboa, 1995, 223 p.), uma apresentação original da Geografia de Portugal, em linguagem simples mas rigorosa, destinada a um vasto leque de leitores.

$\mathrm{Na}$ última dezena de anos, uma das actividades fundamentais a que se dedicou a Professora Suzanne Daveau foi a preparação e a edição das obras de Orlando Ribeiro. No caso da Geografia de Portugal, em quatro volumes (Ed. J.S.C., 1987, 1988, 1889, 1991), o ponto de partida é a Geografia de Portugal de Orlando Ribeiro, publicada em castelhano em 1955, integrada na monumental Geografía de España y Portugal, dirigida por Manuel de Terán, e também a Geografia de Portugal de Hermann Lautensach, que havia sido publicada em alemão e em dois volumes, de 1932 e 1937. Para além da organização e dos comentários, Suzanne Daveau fez uma desenvolvida actualização dessas obras, o que justifica plenamente a co-autoria no trabalho final.

Mas a sua actividade editorial inclui ainda as seguintes obras de Orlando Ribeiro: Iniciação em Geografia Humana (Ed. J.S.C., 1986); Introdução aos Estudos de Geografia Regional (Ed. J.S.C., 1987); Formação de Portugal (ICALP, 1987); Portugal, o Mediterrâneo e o Atlântico (Ed. J.S.C, 1993, fotografia de Jorge Barros); Originalidade da Expansão Portuguesa (Ed. J.S.C., 1994) e, sobretudo, Opúsculos Geográficos, publicação em seis volumes, num total de 2.700 páginas (Fundação Calouste Gulbenkian, Lisboa, entre 1989 e 1995).

Gostaria de prestar aqui a minha sincera homenagem a Suzanne Daveau, por tão grande e persistente dedicação a seu esposo, e assim também à ciência e à cultura portuguesas. 
Muitos são os méritos da Professora Suzanne Daveau, que eu apenas de maneira incompleta e imperfeita tentei salientar. A recente atribuição do grau de Doutor Honoris Causa pela Faculdade de Letras da Universidade de Lisboa, por proposta do Grupo de Geografia, é uma homenagem à sua ilustre carreira de investigadora e de docente universitária, e aos relevantes serviços prestados à Universidade e ao País 